\title{
Intake of Vitamin A, Thiamine, Riboflavin, Vitamin C, and Niacin Among Children Aged 6-11 Years Old - China, 2016-2017
}

\author{
Wei Piao'; Lahong Ju'; Hongyun Fang'; Qiya Guo'; Shuya Cai'; Xiaoli Xu'; Shujuan Li'; \\ Xue Cheng'; Liyun Zhao ${ }^{1, *}$; Dongmei $\mathrm{Yu}^{1, *}$
}

\section{Summary \\ What is already known on this topic? \\ Insufficient intake of vitamins is one of the major nutritional problems in children aged 6-11 years old in China, and the problem is particularly severe for rural populations. \\ What is added by this report? \\ Among children aged 6-11 years old in 2016-2017, the average intakes of vitamin $A$, thiamine, riboflavin, vitamin $C$, and niacin were $336.37 \mu \mathrm{gRAE} / \mathrm{d}$, $0.7 \mathrm{mg} / \mathrm{d}, 0.7 \mathrm{mg} / \mathrm{d}, 51.5 \mathrm{mg} / \mathrm{d}$, and $11.4 \mathrm{mg} / \mathrm{d}$, respectively. The proportions of vitamin intakes reaching recommended nutrient intakes of the 5 nutrients were $18.2 \%, 13.8 \%, 14.95 \%, 24.6 \%$, and $51.3 \%$, respectively. \\ What are the implications for public health practice? \\ Imbalance of nutritional conditions among different regions and populations in China should be seriously prioritized in nutritional improvement. Systematic measures including government policy, economy improvement, education, behavior intervention, and food resource safety should be applied.}

Vitamins are essential substances for life and were recognized by the World Health Organization (WHO) as malnutrition and undernutrition are always accompanied with vitamin deficiency, which has become a significant child health challenge in many developing countries. Millions of children are more susceptible to disease and death due to vitamin deficiency (1). Previous domestic regional surveys in China had shown that significant proportions of school age populations suffered from nutrition deficiency, including insufficient vitamin intakes (2-3). The results drawn from China National Nutrition and Health Survey (2002) and China Nutrition and Health Surveillance (2010-2013) had revealed that vitamin deficiencies were still severe health problems in the
Chinese population, especially in children and adolescents. China Nutrition and Health Surveillance of Children and Lactating Mothers in 2016-2017 was conducted by China CDC in 31 provincial-level administrative divisions (PLADs). Nationally and provincially representativeness of the study population was tested. Multistage stratified random sampling method was used in this survey. Four methods were designed to obtain the survey data, including interviews, physical examinations, laboratory tests, and dietary interviews (4). The study aimed to analyze the nutritional status of the Chinese population, including the conditions of vitamin intakes. The data in this paper were from the China Nutrition and Health Surveillance conducted between 2016 and 2017, which focused on the key vitamin intakes of children aged 6-11 years. This survey found that vitamin deficiencies were still severe in children aged 6-11 years old, and conditions were worse in rural populations. Systematic measures should be applied to solve the nutrition problems in children aged 6-11 years in China.

China Nutrition and Health Surveillance of Children and Lactating Mothers in 2016-2017 was a cross-sectional study conducted in 31 PLADs (4), and data of this paper was collected from the participants in this survey. Four methods were designed to obtain the survey data, including interviews to collect demographic information; physical examinations to observe the indicators of growth; laboratory tests to evaluate health conditions; and dietary interviews to obtain food intake information. The information on vitamins intake was drawn and assessed through 3 consecutive days of 24 hour dietary recalls and household weight records of edible oil, salt, and flavoring. Calculation of vitamins was conducted with reference to China Food Composition Tables (5-6). Study subjects were divided into different groups by sex and regions. The vitamin intakes of subjects were presented as means, standard errors, and 10, 25, 50, 
75, 90 quantiles. Intake amounts of vitamin were assessed by the criteria of dietary reference intakes (DRIs), including estimated average criteria (EAR) and recommended nutrient intakes (RNI) ( 7 ). According to the assessing results, the subjects were allocated into $<$ EAR, EAR-RNI, and $\geq$ RNI groups. SAS (version 9.4, SAS Institute Inc., Cary, NC, USA) was used to conduct all the analyses. The protocol of this study was evaluated and approved by the ethical committee of China CDC (201614).

A total of 8,777 subjects were included for the calculation, with 4,364 males (2,034 in urban areas and 2,330 in rural areas) and 4,413 females (2,111 in urban areas and 2,302 in rural areas). The average ages of subjects were $9.2 \pm 1.6$ in total for both genders. The numbers of subjects for urban areas and rural areas were 4,145 and 4,632, respectively.

The intakes of vitamin $\mathrm{A}$, thiamine, riboflavin, vitamin $C$, and niacin for children aged 6-11 years in China during 2016-2017 were shown in Table 1 and Table 2. The total average intakes of vitamin $\mathrm{A}$, thiamine, riboflavin, vitamin $\mathrm{C}$, and niacin were $336.4 \mu \mathrm{gRAE} / \mathrm{d}, 0.7 \mathrm{mg} / \mathrm{d}, 0.7 \mathrm{mg} / \mathrm{d}, 51.5 \mathrm{mg} / \mathrm{d}$, and $11.4 \mathrm{mg} / \mathrm{d}$, respectively. The total intakes of the five nutrients in urban areas were higher than that in rural areas, and similar trends were observed in different gender groups. For vitamin A, the average intake for males was $402.0 \mu \mathrm{gRAE} / \mathrm{d}$, which was lower than the intakes of females (403.6 $\mu \mathrm{gRAE} / \mathrm{d})$ in urban areas, whereas vitamin A intake in rural areas was higher in males $(283.1 \mu \mathrm{gRAE} / \mathrm{d})$ than that in females $(270.7$ $\mu \mathrm{gRAE} / \mathrm{d})$. The intake characteristics of other four nutrients in both urban areas and rural areas were higher in males than in females.

Table 3 demonstrated the results of assessing the intakes of five nutrients based on EARs and RNIs values. The proportions of intakes that reached the RNIs of vitamin A, thiamine, riboflavin, vitamin C, and niacin were $18.2 \%, 13.8 \%, 14.95 \%, 24.6 \%$, and $51.3 \%$, respectively. The proportions in rural groups were all far below that in urban groups. In gender analyses, the proportions of the fives nutrients intakes reaching RNIs in males were higher than in females, except for the proportions of niacin intakes. The status of nutrient intakes in urban areas was better than that in rural areas, and same trends were observed in gender analyses between the two regions.

TABLE 1. Total intake of vitamins among children aged 6-11 years in China, 2016-2017.

\begin{tabular}{|c|c|c|c|c|c|c|c|}
\hline \multirow{2}{*}{ Nutrients } & \multirow{2}{*}{ Mean } & \multirow{2}{*}{ SD } & \multicolumn{5}{|c|}{ Percentiles } \\
\hline & & & 10 & 25 & 50 & 75 & 90 \\
\hline \multicolumn{8}{|l|}{ Total } \\
\hline Vitamin A ( $\mu \mathrm{gRAE} / \mathrm{d})$ & 336.4 & 362.6 & 88.4 & 153.2 & 252.1 & 408.9 & 630.9 \\
\hline Thiamine $(\mathrm{mg} / \mathrm{d})$ & 0.7 & 0.3 & 0.3 & 0.4 & 0.6 & 0.8 & 1.1 \\
\hline Riboflavin (mg/d) & 0.7 & 0.3 & 0.3 & 0.4 & 0.6 & 0.8 & 1.1 \\
\hline Vitamin C $(\mathrm{mg} / \mathrm{d})$ & 51.5 & 89.5 & 14.0 & 23.7 & 39.6 & 62.6 & 91.7 \\
\hline Niacin $(\mathrm{mg} / \mathrm{d})$ & 11.4 & 5.5 & 5.6 & 7.6 & 10.4 & 13.9 & 18.1 \\
\hline \multicolumn{8}{|l|}{ Male } \\
\hline Vitamin A ( $\mu \mathrm{gRAE} / \mathrm{d})$ & 338.5 & 356.4 & 88.1 & 153.7 & 257.7 & 415.4 & 622.9 \\
\hline Thiamine $(\mathrm{mg} / \mathrm{d})$ & 0.7 & 0.3 & 0.4 & 0.4 & 0.6 & 0.8 & 1.1 \\
\hline Riboflavin (mg/d) & 0.7 & 0.3 & 0.3 & 0.5 & 0.6 & 0.8 & 1.1 \\
\hline Vitamin $C(\mathrm{mg} / \mathrm{d})$ & 52.4 & 107.4 & 13.8 & 23.6 & 39.1 & 62.4 & 91.5 \\
\hline Niacin (mg/d) & 11.6 & 5.9 & 5.7 & 7.7 & 10.6 & 14.2 & 18.5 \\
\hline \multicolumn{8}{|l|}{ Female } \\
\hline Vitamin $\mathrm{A}(\mu \mathrm{gRAE} / \mathrm{d})$ & 334.3 & 368.7 & 88.8 & 152.7 & 248.9 & 404.0 & 635.2 \\
\hline Thiamine $(\mathrm{mg} / \mathrm{d})$ & 0.7 & 0.3 & 0.3 & 0.4 & 0.6 & 0.8 & 1.1 \\
\hline Riboflavin (mg/d) & 0.7 & 0.3 & 0.3 & 0.4 & 0.6 & 0.8 & 1.0 \\
\hline Vitamin C $(\mathrm{mg} / \mathrm{d})$ & 50.7 & 67.3 & 14.0 & 23.8 & 40.1 & 62.9 & 92.1 \\
\hline $\operatorname{Niacin}(\mathrm{mg} / \mathrm{d})$ & 11.1 & 5.2 & 5.5 & 7.4 & 10.2 & 13.6 & 17.7 \\
\hline
\end{tabular}

Abbreviation: $\mathrm{SD}=$ standard deviation. 
TABLE 2. Intake of vitamins among children aged 6-11 years in urban and rural areas in China, 2016-2017.

\begin{tabular}{|c|c|c|c|c|c|c|c|c|c|c|c|c|c|c|}
\hline \multirow{3}{*}{ Nutrients } & \multicolumn{7}{|c|}{ Urban } & \multirow{3}{*}{ Mean } & \multirow{3}{*}{ SD } & \multicolumn{5}{|c|}{ Rural } \\
\hline & \multirow{2}{*}{ Mean } & \multirow{2}{*}{ SD } & \multicolumn{5}{|c|}{ Percentiles } & & & \multicolumn{5}{|c|}{ Percentiles } \\
\hline & & & 10 & 25 & 50 & 75 & 90 & & & 10 & 25 & 50 & 75 & 90 \\
\hline \multicolumn{15}{|l|}{ Total } \\
\hline Vitamin A ( $\mu \mathrm{gRAE} / \mathrm{d})$ & 402.8 & 444.0 & 114.2 & 189.6 & 307.8 & 474.2 & 748.5 & 276.9 & 255.5 & 74.0 & 129.3 & 214.0 & 336.4 & 530.7 \\
\hline Thiamine $(\mathrm{mg} / \mathrm{d})$ & 0.7 & 0.3 & 0.4 & 0.5 & 0.6 & 0.9 & 1.1 & 0.6 & 0.3 & 0.3 & 0.4 & 0.6 & 0.7 & 1.0 \\
\hline Riboflavin (mg/d) & 0.8 & 0.3 & 0.4 & 0.5 & 0.7 & 0.9 & 1.2 & 0.6 & 0.3 & 0.3 & 0.4 & 0.5 & 0.7 & 0.9 \\
\hline Vitamin C $(\mathrm{mg} / \mathrm{d})$ & 55.0 & 97.9 & 14.5 & 25.6 & 43.1 & 66.4 & 97.1 & 48.4 & 81.1 & 13.6 & 22.4 & 36.8 & 59.1 & 87.7 \\
\hline Niacin $(\mathrm{mg} / \mathrm{d})$ & 12.1 & 5.6 & 6.3 & 8.3 & 11.3 & 14.8 & 18.9 & 10.7 & 5.4 & 5.2 & 7.1 & 9.6 & 12.9 & 17.2 \\
\hline \multicolumn{15}{|l|}{ Male } \\
\hline Vitamin A ( $\mu \mathrm{gRAE} / \mathrm{d})$ & 402.0 & 427.3 & 117.4 & 190.6 & 318.1 & 472.7 & 725.2 & 283.1 & 268.2 & 74.1 & 129.2 & 215.8 & 346.0 & 547.4 \\
\hline Thiamine $(\mathrm{mg} / \mathrm{d})$ & 0.7 & 0.3 & 0.4 & 0.5 & 0.7 & 0.9 & 1.1 & 0.6 & 0.3 & 0.3 & 0.4 & 0.6 & 0.8 & 1.0 \\
\hline Riboflavin (mg/d) & 0.8 & 0.3 & 0.4 & 0.5 & 0.7 & 1.0 & 1.2 & 0.6 & 0.3 & 0.3 & 0.4 & 0.5 & 0.7 & 0.9 \\
\hline Vitamin C $(\mathrm{mg} / \mathrm{d})$ & 55.2 & 111.2 & 14.3 & 25.4 & 42.6 & 65.4 & 93.9 & 49.9 & 103.9 & 13.6 & 22.5 & 36.4 & 59.1 & 89.4 \\
\hline Niacin $(m g / d)$ & 12.4 & 5.9 & 6.3 & 8.4 & 11.4 & 15.2 & 19.2 & 11.0 & 5.8 & 5.3 & 7.2 & 9.8 & 13.1 & 17.8 \\
\hline \multicolumn{15}{|l|}{ Female } \\
\hline Vitamin A ( $\mu \mathrm{gRAE} / \mathrm{d})$ & 403.6 & 459.6 & 110.6 & 188.4 & 299.6 & 474.8 & 758.3 & 270.7 & 241.8 & 73.6 & 129.5 & 212.7 & 329.1 & 518.2 \\
\hline Thiamine $(\mathrm{mg} / \mathrm{d})$ & 0.7 & 0.3 & 0.4 & 0.5 & 0.6 & 0.9 & 1.1 & 0.6 & 0.3 & 0.3 & 0.4 & 0.5 & 0.7 & 1.0 \\
\hline Riboflavin (mg/d) & 0.7 & 0.3 & 0.4 & 0.5 & 0.7 & 0.9 & 1.2 & 0.6 & 0.3 & 0.3 & 0.4 & 0.5 & 0.7 & 0.9 \\
\hline Vitamin C $(\mathrm{mg} / \mathrm{d})$ & 54.8 & 83.1 & 14.7 & 25.6 & 43.5 & 67.7 & 100.8 & 46.9 & 48.2 & 13.6 & 22.3 & 37.2 & 58.8 & 85.6 \\
\hline $\operatorname{Niacin}(\mathrm{mg} / \mathrm{d})$ & 11.9 & 5.3 & 6.2 & 8.2 & 11.0 & 14.4 & 18.5 & 10.3 & 5.0 & 5.1 & 6.9 & 9.5 & 12.6 & 16.6 \\
\hline
\end{tabular}

Abbreviation: $\mathrm{SD}=$ standard deviation.

TABLE 3. Distributions of vitamin intake among children aged 6-11 years in China 2016-2017.

\begin{tabular}{|c|c|c|c|c|c|c|c|c|c|}
\hline \multirow{2}{*}{ Nutrients } & \multicolumn{3}{|c|}{ Total (\%) } & \multicolumn{3}{|c|}{ Urban (\%) } & \multicolumn{3}{|c|}{ Rural (\%) } \\
\hline & $<$ EAR & EAR-RNI & $\geq$ RNI & $<$ EAR & EAR-RNI & $\geq$ RNI & $<$ EAR & EAR-RNI & $\geq$ RNI \\
\hline \multicolumn{10}{|l|}{ Total } \\
\hline Vitamin A & 67.4 & 14.5 & 18.2 & 57.0 & 18.3 & 24.7 & 76.6 & 11.0 & 12.3 \\
\hline Thiamine & 72.5 & 13.7 & 13.8 & 66.7 & 16.1 & 17.3 & 77.7 & 11.5 & 10.8 \\
\hline Riboflavin & 71.0 & 14.0 & 15.0 & 60.0 & 17.6 & 22.4 & 80.9 & 10.9 & 8.3 \\
\hline Vitamin C & 66.6 & 8.9 & 24.6 & 62.5 & 9.7 & 27.8 & 70.2 & 8.1 & 21.7 \\
\hline Niacin & 31.4 & 17.4 & 51.3 & 25.0 & 16.3 & 58.8 & 37.1 & 18.3 & 44.6 \\
\hline \multicolumn{10}{|l|}{ Male } \\
\hline Vitamin A & 66.1 & 15.5 & 18.4 & 55.6 & 19.4 & 25.0 & 75.3 & 12.1 & 12.7 \\
\hline Thiamine & 71.6 & 14.1 & 14.3 & 65.7 & 16.6 & 17.8 & 76.8 & 12.0 & 11.2 \\
\hline Riboflavin & 69.4 & 14.3 & 16.3 & 57.3 & 17.7 & 25.1 & 79.9 & 11.5 & 8.6 \\
\hline Vitamin C & 66.8 & 8.5 & 24.7 & 62.9 & 9.4 & 27.7 & 70.2 & 7.7 & 22.1 \\
\hline Niacin & 34.2 & 16.6 & 49.2 & 27.8 & 15.2 & 56.9 & 39.7 & 17.8 & 42.5 \\
\hline \multicolumn{10}{|l|}{ Female } \\
\hline Vitamin A & 68.7 & 13.4 & 17.9 & 58.5 & 17.2 & 24.4 & 78.0 & 10.0 & 12.0 \\
\hline Thiamine & 73.4 & 13.2 & 13.4 & 67.6 & 15.6 & 16.8 & 78.7 & 11.0 & 10.3 \\
\hline Riboflavin & 72.7 & 13.7 & 13.6 & 62.7 & 17.5 & 19.9 & 81.8 & 10.3 & 7.9 \\
\hline Vitamin C & 66.3 & 9.2 & 24.5 & 62.1 & 10.0 & 28.0 & 70.1 & 8.6 & 21.3 \\
\hline Niacin & 28.6 & 18.1 & 53.3 & 22.2 & 17.3 & 60.5 & 34.4 & 18.9 & 46.8 \\
\hline
\end{tabular}

Abbreviation: $E A R=e s t i m a t e d$ average criteria; $\mathrm{RNI}=$ recommended nutrient intakes. 


\section{DISCUSSION}

Although the nutritional conditions for Chinese population have improved rapidly in recently years, insufficient vitamin intakes are constantly considered as public health problems. For children and adolescents, vitamin deficiencies affect not only physical health, but also ability to work during adulthood. Different from protein-energy malnutrition (PEM), vitamin deficiencies are always latent. Assessment of dietary nutrient intake is one of the reasonable methods to understand nutritional conditions of individuals and the overall population.

In this study, the intake levels of vitamin $A$, thiamine, riboflavin, vitamin $\mathrm{C}$, and niacin were assessed based on DRIs. Among total participants, the average thiamine intake for males was $0.7 \mathrm{mg} / \mathrm{d}$ and the average vitamin $\mathrm{C}$ intake for females was $50.7 \mathrm{mg} / \mathrm{d}$, both of which were lower than the results in China Nutrition and Health Surveillance 2010-2013. Compared with 2010-2013, all intakes of five nutrients in urban areas increased for both males and females, but in rural areas, the intake of thiamine for males $(0.6 \mathrm{mg} / \mathrm{d})$ and the intake of vitamin $\mathrm{C}$ for females $(46.9 \mathrm{mg} / \mathrm{d})$ were lower than that in 2010-2013. The gap between existing levels and recommended levels of intake for the five nutrients for children aged 6-11 years in China is concerning, especially as the intake levels of these nutrients were far below corresponding levels in the United States, the United Kingdom, and Japan. The large gaps between urban areas and rural areas for the 5 nutrient intakes were quite obvious, and that could be concluded in the results (8-10). Compared with 2010-2013, although most proportions of reaching or succeding the RNIs for each nutrient were slightly increased, the proportions of under EARs remained problematic. The results of this study suggested that the nutritional status of urban children was not adequate and was worse for rural children.

Generally, vitamin deficiencies were still severe in children aged 6-11 years old, and conditions were worse in rural populations. The results from national nutrition survey in 2002, 2010-2013, and 2016-2017 showed that the Chinese nutrition and health have achieved significant improvements overall, but the imbalance among different areas cannot be ignored. It is imperative that nutritional improvement actions should be implemented accurately. Government policy, economic improvement, education, behavior intervention, and food resource safety are all potential factors that can affect the results of nutrition improvement. In "Healthy China 2030", rational diet and relative measures have been emphasized. Nutrition Improvement Program for Rural Compulsory Education Students had been performed to address nutritional problems for school-age children in rural areas since November 2011. To solve these problems, systematic measures should be applied.

This study was subject to at least two limitations. First, the data for 3 consecutive days of 24 hour dietary recalls were collected from children, teachers, care givers, schools, or families, so the accuracy of the results might be affected by recall bias. Second, some of the food compositions were needed to be updated due to the improvements and adjustments of crop varieties. These compositions might affect estimates for nutritional intake due to a lack of consistency.

Acknowledgment: Project teams from China CDC, provincial-level CDCs, and county/district-level CDCs, local school staff, and all participants.

Conflicts of interest: No conflicts of interest.

Funding: National Health Commission of the People's Republic of China Medical Reform Major Program: China Nutrition and Health Surveillance of Children and Lactating Mothers (2016-2017).

doi: $10.46234 / \mathrm{ccdcw} 2021.067$

\# Corresponding authors: Liyun Zhao, zhaoly@ninh.chinacdc.cn; Dongmei Yu, yudm@ninh.chinacdc.cn.

\footnotetext{
${ }^{1}$ National Institute for Nutrition and Health, Chinese Center for Disease Control and Prevention; Key Laboratory of Trace Element Nutrition, National Health Commission of the People's Republic of China, Beijing, China.
}

Submitted: March 02, 2021; Accepted: March 11, 2021

\section{REFERENCES}

1. World Health Organization. World health statistics 2020: monitoring health for the SDGs, sustainable development goals. Geneva: World Health Organization; 2020. https://apps.who.int/iris/bitstream/handle/ 10665/332070/9789240005105-eng.pdf. [2021-03-10].

2. Ji GY, Hong XM, Chen ZH, Tan JB, Jiang Q, Peng JW, et al. Prevalence of malnutrition status in children and adolescents in Guangdong Province, 2002-2012. J Hyg Res 2019;48(6):907 - 12. http://dx.doi.org/10.19813/j.cnki.weishengyanjiu.2019.06.008. (In Chinese).

3. Zhao J, Wang Z, Ba L, Lin N, Wei YF. Dietary nutrients intake status of primary and middle school students in Chaoyang district of Beijing City in 2015. Food Nutr China 2018;24(6): 82-5. https://kns.cnki.net/$\mathrm{kcms} /$ detail/detail.aspx?dbcode=CJFD\&dbnameCJFDLAST2018\&filen am=ZGWY201806020\&vv3u6ZHGjrHUdXKvJjbDW1OtyJ5Q2lpM qD7J0hcBv3XeCptjFDBvcrqlB6kQ3IbIP. (In Chinese).

4. Yu DM, Zhao LY, Zhang J, Yang ZY, Yang LC, Huang J, et al. China nutrition and health surveys (1982-2017). China CDC Wkly 2021;3 
(9):193 - 5. http://dx.doi.org/10.46234/ccdcw2021.058.

5. National Institute for Nutrition and Health, Chinese Center for Disease Control and Prevention. China food composition tables standard edition volume I. 6th ed. Beijing: Peking University Medical Press. 2018. (In Chinese).

6. National Institute for Nutrition and Health, Chinese Center for Disease Control and Prevention. China food composition tables standard edition Volume II. 6th ed. Beijing: Peking University Medical Press. 2019. (In Chinese).

7. Chinese Nutrition Society. Chinese dietary reference intakes (2013). Beijing: China Science Publishing \& Media Ltd. 2014. (In Chinese).

8. Public Health England. National diet and nutrition survey results from years 1,2, 3 and 4 (combined) of the rolling programme (2008/ 2009-2011/2012). Public Health England, Food Standards Agency; 2014. https://assets.publishing.service.gov.uk/government/uploads/ system/uploads/attachment_data/file/310995/NDNS_Y1_to_4_UK_re port.pdf. [2021-03-11].

9. Japan ministry of health, labor and welfare national health and nutrition survey. https://www.mhlw.go.jp/bunya/kenkou/eiyou/dl/h28-houkoku. pdf. [2021-03-11]. (In Japanese).

10. USDA. What we eat in America, NHANES 2017-2018, individuals 2 years and over (excluding breast-fed children), day 1 . https://www.ars. usda.gov/nea/bhnrc/fsrg. [2021-03-11]. 